\title{
Research on Efficient Group Organization in Active Learning
}

\author{
Kodai Saito, Mitsuaki Yamada, Tsukasa Sato, Ryoji Onodera, Michiaki Shishido* \\ National Institute of Technology, Tsuruoka College, 104 Sawada Inooka, Tsuruoka 997-8511, Japan \\ *Corresponding Author: m-shishido@tsuruoka-nct.ac.jp
}

\begin{abstract}
In recent years, active learning with group work has been adopted in educational institution lessons. Application of group work is expected to create student's independence and cooperativeness, thinking faculty, expressiveness and so on. However, in group work, there are drawbacks that adversely affect the progress and outcomes of activities if an imbalance occurs in the personality and characteristics among members of the group. Therefore, in order to maximize the learning effect of group work, balancing the performance exerted by the organized group is indispensable. In this research, a complementary group organization model "Formation of Ability Averaging" (FAA) considering characteristics and problems of individuals was proposed. Also, in order to demonstrate the characteristics of capacity averaging organization, several organization methods were compared. In the experiment, Think-Pair-Share group work was executed with the history of general studies as a theme. The superiority was evaluated by questionnaire survey using Visual Analog Scale after activity. As a result, in the Ability Averaging Formation designating the positions within the group, the interest that leads to self-study after class was high, and the effect of student's motivation to learn was observed. In addition, FAA was able to determine the condition of organization by the organizer, so the number of groups organized was larger than that of the other, indicating high degree of freedom and versatility.
\end{abstract}

Keywords: Active Learning, Group Work, Group Formation, Team Management.

\section{Introduction}

Recently, decline of academic ability of students is widely discussed. However, its reality is a decline in confidence of individuals and a lowering motivation to learn, which occurs when students cannot capture the significance of learning with their future prospects ${ }^{(1)}$. This problem is a factor that related to hindrance of development of human resources responsible for society, and it is a social problem requiring continuous and comprehensive solution. Especially in the problem solving approach from the higher education field, the Ministry of Education, Culture, Sports, Science and Technology (MEXT) has started the construction of a lifelong learning society based on the philosophy of "independence," collaboration, "creation"(2). Above all, for the restructuring of the that educational process, independent and cooperative active learning is recommended for learning means ${ }^{(3)}$. Active learning is a generic name of teaching / learning method which incorporates participation. This is different from the one-way lecture style by teachers. The basic feature of active learning is that the students' thinking requires students action. The purpose of learning is not limited to the accumulation of knowledge. Knowledge is acquired by performing knowledge and skills.

At least 30 types of active learning are confirmed currently. In particular, the majority of the classified methods are occupied by group work in which small groups are formed. Since this group work requires student's independence, most of them are positioned as divergent learning. Therefore, it is expected to form student's subjectivity and cooperativeness, thinking faculty, expressiveness by active learning. In the group work it is reported that at the university, an basic skills for member of society is trained ${ }^{(4)}$ and improvement of the presentation skill ${ }^{(5)}$ were recognized. Learning effects in areas with expertise such as nursing science and nursing care welfare are also reported ${ }^{(6)}$. However, in the study on the learning effect of group work by Mr. Maeda et al., the influence on the learning effect due to the disparity between the grouped groups is pointed out ${ }^{(7)}$. Group work is considered to have an adverse effect on progress and achievement of activities if the members and members of the group have disproportion 
in character and characteristics. When this drawback is improved, the performance exerted by the organized group is balanced. As a result, it is expected that subjective and collaborative growth of students as a whole will be achieved by applying group work.

In this research, a group organization model "Formation of Ability Averaging" (FAA) complementing within the group considering characteristics and qualities of individuals was proposed and aimed at deployment to educational institutions. In order to establish the learning effect which is not influenced by the field of study, the learning effects of multiple organizational methods including FAA were compared. In particular, a questionnaire survey was conducted on students' learning awareness by group work for students belonging to the National Institute of Technology, and changes in consciousness by different organizational methods were evaluated.

\section{Group organization method}

\subsection{Formation of Five Factors \& Stress theory (FFFS)}

Five Factors \& Stress theory (FFS), proposed by Mr. Kobayashi, is based on psychology and is used to create the organization of the appropriate membering ${ }^{(8)}$. The character of each person is digitized by the strength of Five Factors and Stress and it is classified into plural types defined by FFS. 80 questions prepared beforehand (30 questions in simplified version) are answered to decide the group members. Each question is associated with either of five factors, and responses are scored and aggregated for each of the five factors.

Table 1 lists the five factors of the thinking behavior ${ }^{(8)(9)}$. Factors are set according to thinking behavior characteristics. Everyone has different factors, and the characteristics are emerged as the effect of different. When a particular factor acts in excess, the influence of that factor is attributable to the person's strengths and weaknesses. After aggregating the questions, the type of the target person is classified by factors that marked high scores.

Table 2 lists the four typical types of classification by $\mathrm{FFS}^{(9)}$. Since FFS is useful for the organization of project teams in business, the characteristics of business suitable for the type are indicated. Therefore, an efficient business system is constructed by adjusting the type of employees that belong to the team.

Figure 1 shows the classification distribution of four types by $\mathrm{FFS}^{(9)}$. The factors effectiing on humans are not limited to a single factor, so classification by summation is not a complete indicator. When there are more than two people classified as the same type, it is necessary to consider at which position in the distribution the person is classified by the influence of other factors. Based on these characteristics, students were classified and groups were organized.

Table 1. Five factors of the thought behavior ${ }^{(8)(9)}$.

\begin{tabular}{l|l}
\hline \multicolumn{1}{c|}{ Factor } & \multicolumn{1}{c}{ Characteristic example } \\
\hline A. Condensable & Have strong sense of own values. \\
\hline B. Receptive & External happiness becomes own happiness. \\
\hline C. Discriminative & Separate conflicts of own situation. \\
\hline D. Diffusible & Expand and develop yourself. \\
\hline E. Preservative & Maintain and protect yourself. \\
\hline
\end{tabular}

Table 2. Four typical types of classification by $\operatorname{FFS}^{(9)}$.

\begin{tabular}{|c|c|}
\hline Type & Characteristic example \\
\hline $\begin{array}{l}\text { Leadership } \\
\text { (LM) }\end{array}$ & $\begin{array}{l}\text { Have strong mental strength, mission sense, } \\
\text { determination, and being proactive. } \\
\text { Probability to unnecessarily make inner enemies and } \\
\text { it is likely to be forced to independence. }\end{array}$ \\
\hline $\begin{array}{c}\text { Management } \\
\text { (ML) }\end{array}$ & $\begin{array}{l}\text { In the case of commercial organizations, focus } \\
\text { attention on cost reduction, adjust and maintain } \\
\text { existing survival of organization. } \\
\text {. Reluctantly respond to business with uncertainty. }\end{array}$ \\
\hline $\begin{array}{l}\text { Tag Board } \\
\text { (TG) }\end{array}$ & $\begin{array}{l}\text { Analogize the trend of the new society from the latest } \\
\text { piecemeal information and besuccessful promptly } \\
\text { without fear of risk. } \\
\text { - It is more likely to be distracted by new challenges } \\
\text { than organization maintenance. }\end{array}$ \\
\hline $\begin{array}{c}\text { Anchor } \\
\text { (AN) }\end{array}$ & $\begin{array}{l}\text { Work faithfully and steadily to instructions and } \\
\text { orders again, with the values and the sense authority } \\
\text { formed up till now. } \\
\text { Reluctantly make themselves leading others. }\end{array}$ \\
\hline
\end{tabular}

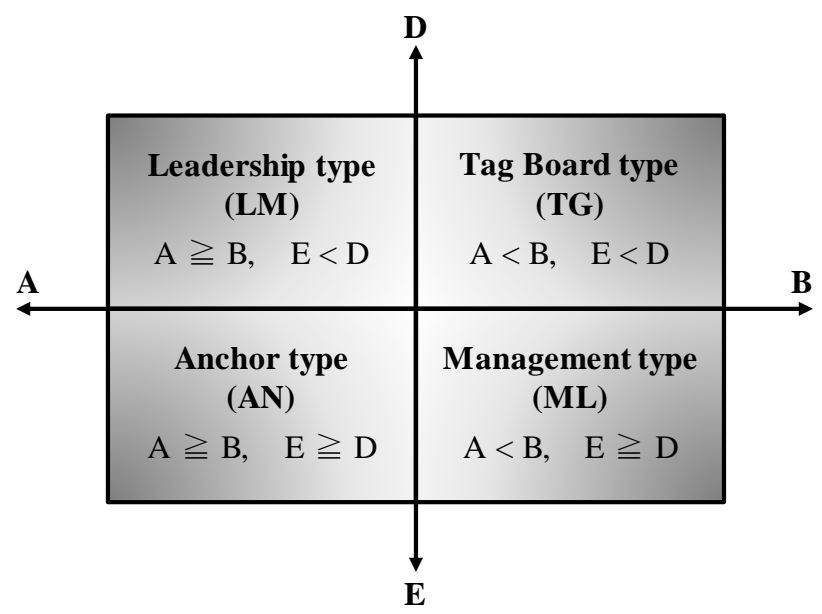

Fig. 1. Classification distribution of four types by $\operatorname{FFS}^{(9)}$. 


\subsection{Formation of Ability Averaging (FAA)}

FAA is a method in which the average capability value of the target group is obtained from the prior questionnaire and groups are compiled after calculating the ability value between the groups from the average value. Since this method is an organization method based on a mathematical model, it has the flexibly to respond to the variation of the knitting condition. In this research, FAA will be introduced to balance the ability value as a performance that demonstrates the ability value of the group.

Figure 2 shows the flow of FAA. More than two arbitrary indices are determined by the faculty to organize the group. The ability value for each student's index is determined from the prior questionnaire, and the class ability average value of each index is obtained. The number of groups generated by organization and the number of members making up each group are determined, and all combinations organized under that condition are calculated. The ability value of each index of the group obtained by combination is recognized as the total value of the ability values of the group members. Group members is determined so that the difference between the ability value of each group and the class ability average value is minimized. At this time, the difference is obtained by the following equation.

$$
\begin{aligned}
\operatorname{Group}(i)_{\text {Difference }} & =\left|\sum_{i} a_{1}^{(i)}-r \overline{a_{1}}\right|^{2} \\
& +\left|\sum_{i} a_{2}^{(i)}-r \overline{a_{2}}\right|^{2} \\
& +\cdots \\
& +\left|\sum_{i} a_{k}^{(i)}-r \overline{a_{k}}\right|^{2}
\end{aligned}
$$

Here, $i$ is a member constituting a group, $a$ is an index, and $k$ is a maximum number of indices.

\section{Experimental method}

\subsection{Group work}

In order to investigate the change of the student's learning consciousness by group organization method, group work was introduced to the actual class and the experiment was executed. In addition, the number of experiments was set to 3. As the experiment was repeated, the group organization method and conditions were adjusted. The survey target and introduced group work are shown below.

\section{$<$ Subject $>$}

History I

\section{$<$ Participants $>$}

National Institute of Technology, Tsuruoka College Department of Creative Engineering. A total of 159 students in 4 classes in the second grade.

\section{$<$ Research period $>$}

From June 2017 to July 2017

\section{$<$ Group organization method $>$}

Among the three experiments, the second and third experiments were set up with different conditions for each of the four classes, and the groups were organized.

Table 3 lists the group organization method. Formation of the seat order (FSO) is the grouping of almost random sampling in which groups are formed according to the seating arrangement. In the FFFS, the classification of students was classified into four types (LM, ML, TG, AN),

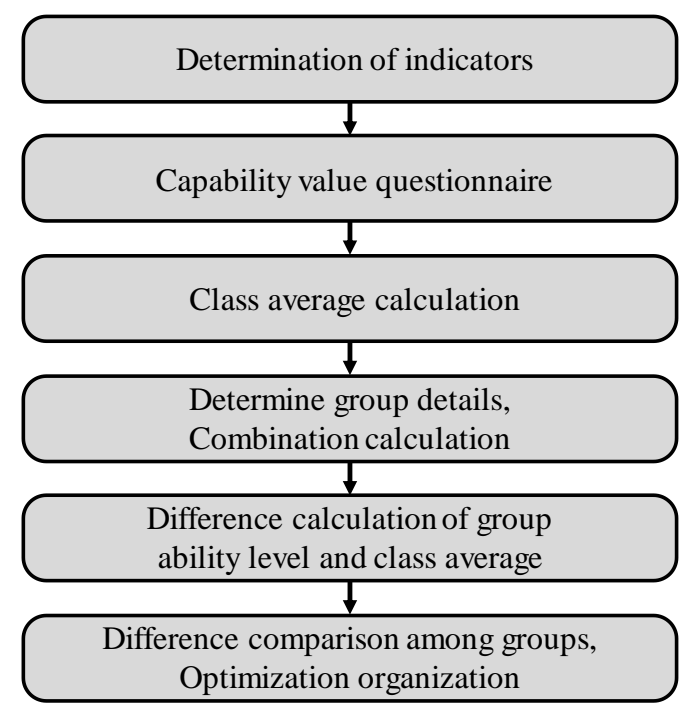

Fig. 2. Flow of FAA.

Table 3. Group organization method.

\begin{tabular}{|c|c|c|c|}
\hline \multirow{2}{*}{ Class } & \multicolumn{3}{|c|}{$\begin{array}{c}\text { Organization method } \\
\text { (Number of groups formed / Total number of groups) }\end{array}$} \\
\cline { 2 - 4 } & First time & Second time & Third time \\
\hline \multirow{2}{*}{ A } & $\begin{array}{c}\text { FOS } \\
(9 / 10)\end{array}$ & $\begin{array}{c}\text { Homogeneous } \\
\text { type of FFFS } \\
(8 / 10)\end{array}$ & $\begin{array}{c}\text { FAA } \\
(8 / 10)\end{array}$ \\
\hline \multirow{2}{*}{ B } & FOS & $\begin{array}{c}\text { FOS } \\
(10 / 10)\end{array}$ & $\begin{array}{c}\text { FOS } \\
(10 / 10)\end{array}$ \\
\hline C & $\begin{array}{c}\text { FOS } \\
(9 / 10)\end{array}$ & $\begin{array}{c}\text { Complementary } \\
\text { type of FFFS } \\
(5 / 10)\end{array}$ & $\begin{array}{c}\text { FAA } \\
(8 / 10)\end{array}$ \\
\hline D & $\begin{array}{c}\text { FOS } \\
(10 / 10)\end{array}$ & $\begin{array}{c}\text { Complementary } \\
\text { type of FFFS } \\
(5 / 10)\end{array}$ & $\begin{array}{c}\text { FAA } \\
(8 / 10)\end{array}$ \\
\hline
\end{tabular}


and a homogeneous type emphasizing efficiency and complementary type emphasizing creativity were organized $^{(10)}$. In addition, the indicators of FAA were as follows, $\alpha_{1}$ : motivation to learn, $\alpha_{2}$ : leadership ability, $\alpha_{3}$ : communication ability.

The number of constituent members of each group was set to 4 , and the number of groups was set to 10 groups for 40 people in one class. Also, there were only 39 people in Class $\mathrm{C}$, and a group of 3 members was organized in one group. In Class $\mathrm{A}$, there was one absentee at the first lesson, and class $\mathrm{C}$ was one less than other classes, so 9 groups were organized by FSO. In the homogeneous organization of FFFS, the condition was set when all the types belonging to the group were satisfied, and 8 groups were organized. The breakdown of the group was two LM types, three ML types, one TG type and two AN types. On the other hand, in the complementary type organization, supplementation of all four types was conditional, and five groups were organized for both Class C and Class D. In FAA, two groups with a large difference between the group's ability value and the class ability average value were excluded, and 8 groups were organized.

In all group work, the role shared in the group was chair person, secretary, speaker / achievement presenter, and timekeeper. In addition, roles within the group were designated in class D, which forming groups using FFFS, FAA.

\section{$<$ Form of Lecture $>$}

The form of lecture was a group work of investigative learning based on Think-Pair-Share ${ }^{(11)}$ proposed to Lyman, FT. Think-Pair-Share is active learning, and personal opinion is shared with others to deepen understanding by responding to teacher's questions ${ }^{(12)}$. In addition, gradual group work by individuals, pairs, groups is done. In the second half of class hours, opinions expressed in group work were presented by representatives of each group. Since the lecture time is as short as 90 minutes, in this experiment group work was done without pair work after personal learning.

\subsection{Survey method}

As for survey of student's consciousness, questionnaire was done at the end of each lesson. The investigation method is shown below.

\section{$<$ Survey method $>$}

Figure 3 shows the question contents of the questionnaire. The questionnaire was answered by the students after group work. At this time, only Q6 was regarded as a selective answer. For other questions, Visual
Analogue Scale (VAS) was used in answering. Subjective pain and psychological state are evaluated quantitatively by VAS and it is used for questionnaire of medical scene ${ }^{(13)}$.

Figure 4 shows Visual Analogue Scale ${ }^{(14)}$. The question is answered by a $100 \mathrm{~mm}$ straight line with the minimum at the left end and the maximum index at the right end. The sense of the respondent is represented visually by writing " $x$ " at the position corresponding to the degree of the current index. In the analysis, the length from the left end, being the minimum value to " $x$ " is measured, and the measured value is scored. When this score is 7 or more, it corresponds to that index and the validity is guaranteed ${ }^{(14)}$.

\section{<Aggregation method>}

In the aggregation, a histogram was used to compare the range of the student's consciousness. The measured value answered by VAS was judged to correspond to the index by observation of $70 \mathrm{~mm}$ or more.

Q1. Have you been interested in what we covered in today's lesson?

Q2. Did you understand the contents of today's lesson?

Q3. During this lesson, did you want to voluntarily investigate the issue?

Q4. Did you express your opinion within this group?

Q5. Did you understand your role within this group?

Q6. What did you do specifically in this group? Please choose one.
A. Chaired
B. Secretary
C. Speaker / Achievement presenter
D. Other

Q7. Have you fulfilled your role within this group?

Q8. Are you satisfied with this group?

Q9. Do you want to do group work again in the future?

Q10. Do you want to further investigate the contents taken up in this class in the future?

Fig. 3. Question contents of the questionnaire.

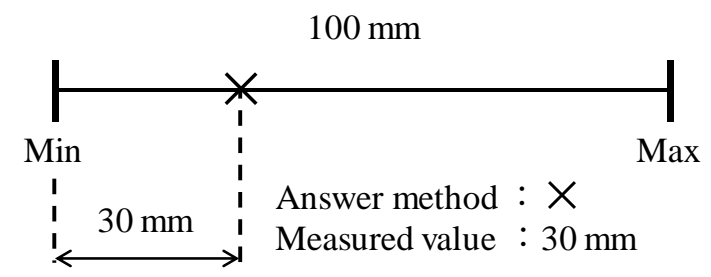

Fig. 4. Visual Analogue Scale ${ }^{(14)}$. 


\section{$<$ Ethical considerations $>$}

Prior to the survey, students were informed that the questionnaire would not be anonymous, that the content would be used for research purposes, that personal information would not be identifiable from the published statistical data, and that the content of the questionnaire would not affect their grades. Answering the questionnaire was taken as consent to cooperate with the study.

\section{Survey results}

Here, the results of the questionnaire survey are shown on the questionnaire item "Q10. Do you want to further investigate the contents taken up in this class in the future?"

Figure 5 shows the questionnaire results for each class. The first group work was defined as the FSO and the mode of Class A and Class B was confirmed in the class of 45 to 50. The mode was confirmed in the class $\mathrm{C}$ of 50 to 55 and the class D of 55 to 60 . The number of students who corresponded to the question was 3 students in class A, 12 in class B, 8 in class $\mathrm{C}$, and 10 in class D.

In the second group work, the mode of Class B was confirmed in the same 40 to 50 class as the first result. In the FFFS, the mode of class A organized in homogeneous type became a class of 30 to 35 , showing a significant decrease compared to the FSO which is a random extraction. There was no significant change compared to FSO for class C and class D with complementary type. The number of people who corresponded to the question was confirmed for 4 students in class A, 8 in class B, 6 in class C, and 8 in class D.

In the third group work, there was no remarkable tendency about the class B histogram class. In the three classes to which FAA was applied, outstanding results were not seen in the questionnaire of Class A and Class C, and no difference was observed in the distribution tendency of the histogram class compared with the initial FSO. On the other hand, in Class $\mathrm{D}$, there were about two respondents in the ranks of 0 to 10 , however, overall it was highly evaluated and the mode was confirmed to increase compared with the FSO. The number of people who corresponded to the question was for 5 people in class A, 15 in class B, 9 in class C, and 14 in class D.

\section{Discussion}

Depending on group organization pattern during group work, great attention was paid to changes in students' willingness to learn. In addition, sign test was adopted in FSO and FFFS, comparison of FSO and FAA. In the sign test, the superiority or inferiority of the data is discriminated with respect to two corresponding specimens. Therefore, the students in the group shown in Table 3 were tested.

Table 4 lists the characteristics of homogeneous group of FFS ${ }^{(10)}$. The homogeneous group of LM type, ML type, AN type, with cooperation among members, the viewpoint of the entire group is focused on the activity with the purpose in mind. In addition, in the TG type homogeneous group, the TG type's unique idea interacts with each other, and as a result, it is activated toward the purpose of the group. In the FFFS of this experiment, an overall low evaluation of class A organized into complementary type and class A organized into homogeneous type compared with class D was confirmed. In comparison with FSO, the number of respondents who responded poorly increased and no significant difference by sign test was confirmed. Although this group work was a short-term activity, it is possible that the developmental nature of the discussion became poor and the expected group work of the expected progress was not made. In the activities during the experiment, it was confirmed that a multi-type mixed group organized by surplus personnel of organization engaged in a more active discussion than the group organized in homogeneous type. In addition, the evaluation of class $C$ and class D organized into complementary type was not superior compared to each FSO, and no significant difference by sign test was

Table 4. Characteristics of homogeneous group of FFS ${ }^{(10)}$.

\begin{tabular}{|l|l|l|}
\hline \multicolumn{2}{|c|}{ Homogeneous group } & Characteristic \\
$※ \mathrm{ML}, \mathrm{AN}$ as well & 1). Good relationships within the group are easy to be formed \\
and discussions are introduced quickly.
\end{tabular}




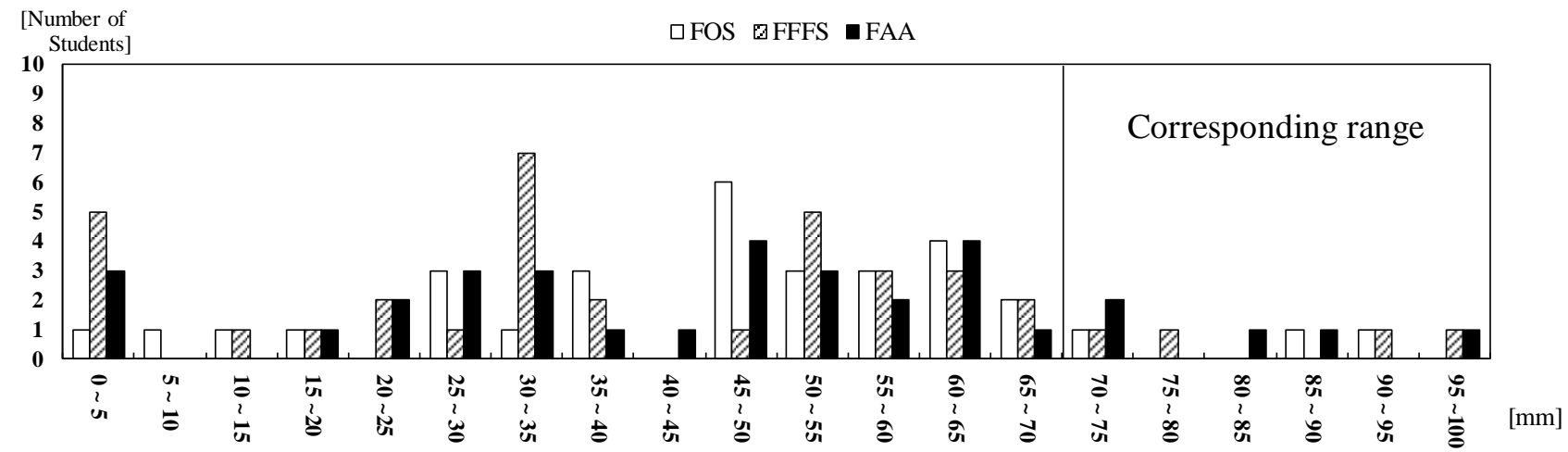

(a) Class $\mathrm{A}$

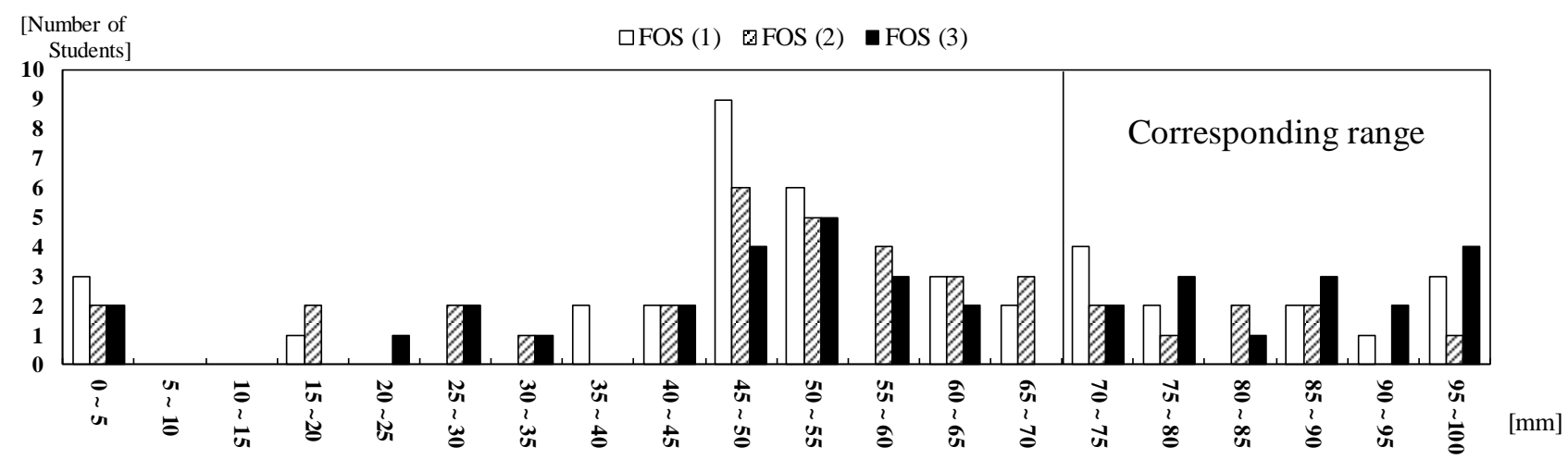

(b) Class B

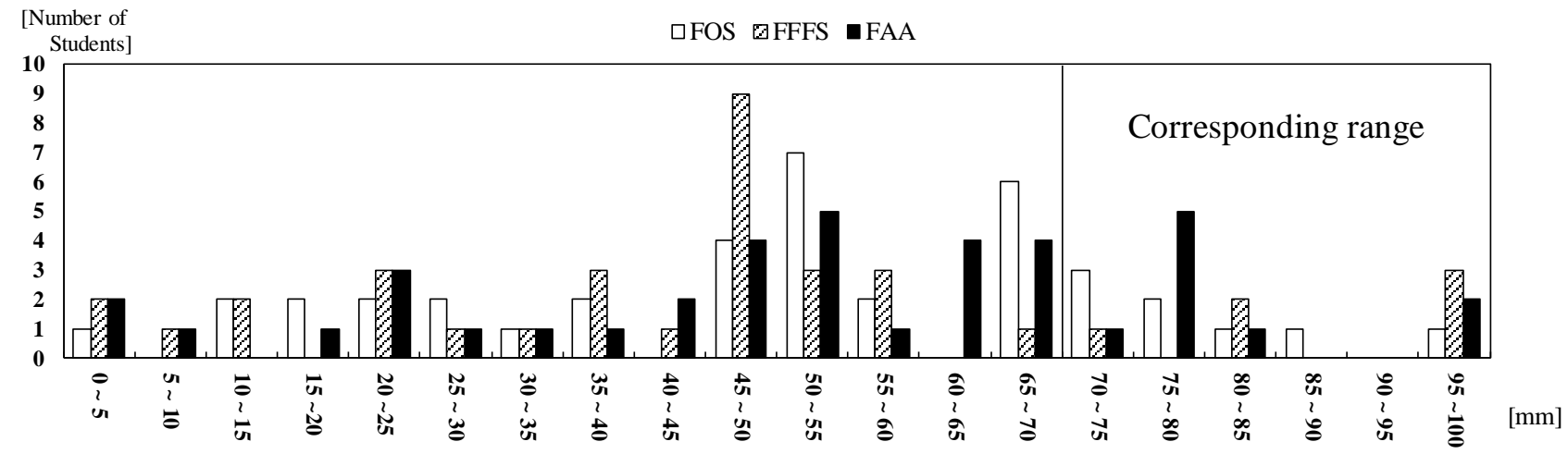

(c) Class $\mathrm{C}$

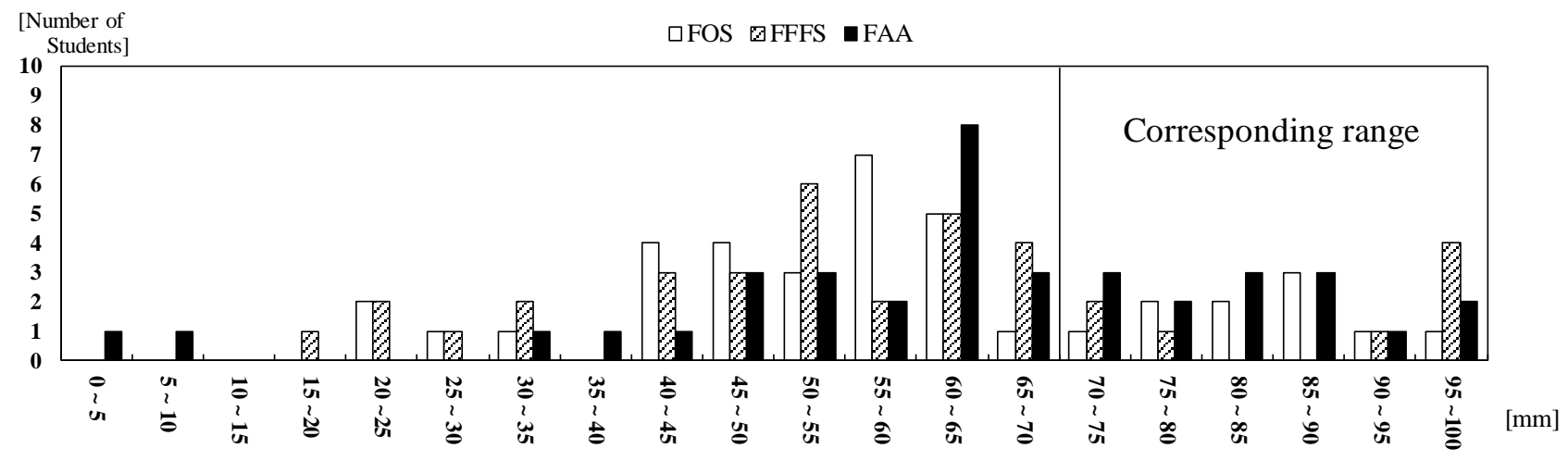

(d) Class D

Fig. 5. Questionnaire results for each class. 
confirmed. FFS is a method mainly used for organizing project teams of companies, and the activities after formation are aimed at profit creation and profit pursuit. Therefore, the roles of individuals within the team are clear, and it is in an environment where responsibility and results are required. The subject of this experiment is a student, and there is little burden of being required for responsibility and results when the goal is learning. Therefore, both the homogeneous type and the complementary type are considered to have failed to fully demonstrate their role in accordance with the type at the time of group work.

In FAA, a high evaluation of the questionnaire of class $\mathrm{D}$ that specified the role was confirmed compared with class A and class C. In comparison with each class FSO, neither Class A nor Class $\mathrm{C}$ had a distinct advantage, and no significant difference by sign test was confirmed. On the other hand, in the sign test for Class D, a significant difference was confirmed in FAA's response compared to FSO. In other words, the group work of FAA increased motivation for learning rather than FSO, suggesting an increase in the number of students who felt they wanted to keep on actively self-studying the content of the lesson. In Class D, roles are designated when organizing the group, it takes less time for students to understand their roles, smooth group work is observed than other classes, and it is thought that the motivation for learning has been improved.

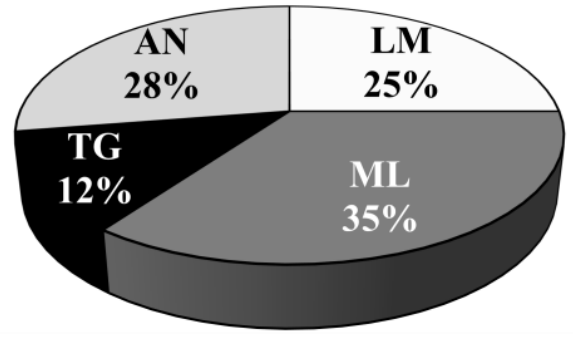

(a) Class A

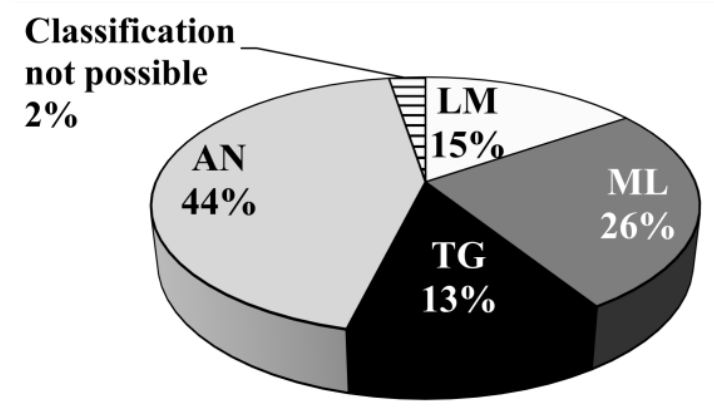

(c) Class C
Figure 6 shows the ratio of FFS theoretical classification type by class. For class B that applied only for FSO, FFS's preliminary questionnaire be answered at the same time as other classes. Looking at the classification result, a certain number of students classified as ML type and AN type in all classes is confirmed as 25 to $45 \%$. However, the leader role LM type student is lower than the above type, and the idea man TG type students are confirmed to be even more rare. Considering this data, we compare the number of groups organized by FFFS and FAA. FFFS organized eight homogeneous types and five complementary types. On the other hand, 8 FAA organized. In FFFS, the type of unbalance in the population affects the number of groups that can be organized, and the number of groups that become complete complementary type is limited. However, in FAA, the number of groups which are not currently averaged can be a small number, and in this experiment $80 \%$ of the total was averaged. From this, it is suggested that FAA is highly versatile as it is calculated based on the average capacity value of the population, and is effective as a method of balancing performance between groups. In addition, the ability to average the capabilities of all groups to be organized is a subject to be solved in the future. (In this experiment, since the effective width of VAS is not taken into consideration, and consideration of the effective width by simultaneous measurement of multiple psychometric

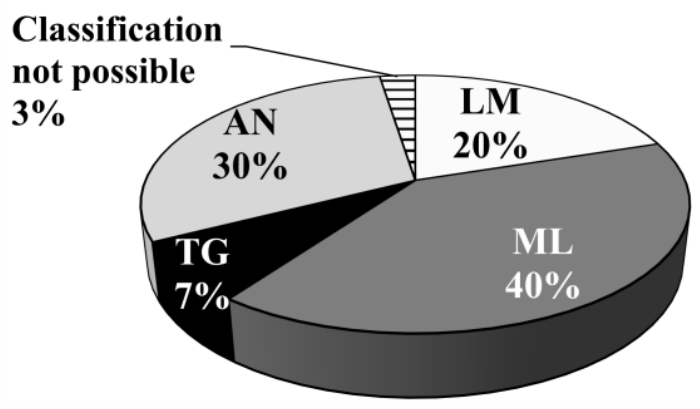

(b) Class B

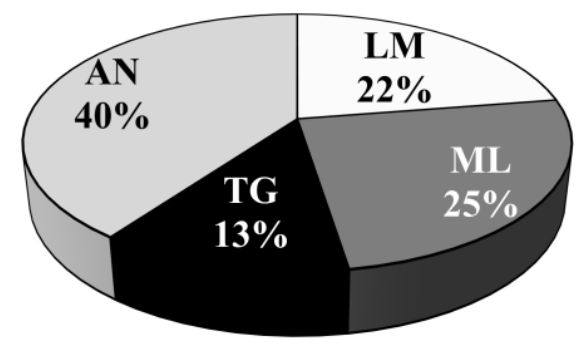

(d) Class D

Fig. 6. Ratio of FFS theoretical classification type by class. 
methods is required for more reliable evaluation.)

In the National Institute of Technology, where students are specializing in industry, history is included in general subjects to acquire culture. Therefore, less time is required for lessons compared to practical training and experiments to master skills. However, in the group work with its history as a theme, the effectiveness was confirmed in students' willingness to learn by FAA's role designation. From this, it is expected to enhance student's motivation for learning by applying this method to their majors and practical training.

\section{Conclusions}

Questionnaires on student's learning awareness by group work for students belonging to the National Institute of Technology and evaluated changes in consciousness by different organization methods. A summary of the results obtained is given below.

(1) Completely complementary type organization shows higher versatility of FAA which can manipulate parameters than FFFS.

(2) In FAA, by designating the role of group work, the effect of improving student willingness to learn was confirmed.

(3) For full-scale introduction of FAA, consideration of an algorithm that does not generate a small number of groups that are not averaged at the time of formation is considered as a task to be considered.

\section{Acknowledgment}

This work was supported by KAKENHI Grant Number JP16K04732.

\section{References}

(1) Yoshiyuki Shimoda : "A Study on Comprehensive Strategy for Increasing Motivation of Learning Through Development of Teaching Materials of "Utilization / Exploration Type Education" -" [in Japanese], 2007

(2) MEXT : "Second Phase Educational Promotion Basic Plan (Outline)" [in Japanese], 2013-2017

(3) Central Council for Education : "Supplementary materials on educational goals / contents, learning / teaching methods, and learning evaluation methods" [in Japanese], June 9, 2015

(4) Hiroshi Yoshida, and Kazuhide Kanenishi :
"Achievements and Problems of Interactive teaching approach - Throughout practice of Hashimoto Method - " [in Japanese], Journal of University Education Research, Vol. 8, pp. 128-137, 2011

(5) Takao Hanabusa, and Hiroshi Kawakami : "Creation Learning and Presentation Evaluation" [in Japanese], Journal of University Education Research, Vol. 1, pp. 83-86, 2004

(6) Fujiko Terada : "-Process of care- curriculum development through group work" [in Japanese], Journal of Hirosaki University of Health and Welfare Junior College, Vol. 2, No. 1, pp. 51-58, 2014

(7) Yukiko Maeda, and Yasuyo Masuda : "Study on Learning Effect of Group Works in Psychiatric Nursing - toward fostering basic academic thinking and skills -" [in Japanese], Journal of Kyushu University of Nursing and Social Welfare, Vol. 8, No. 1, pp. 131-124, 2006

(8) Keichi Kobayasi : "Introductory Self Coaching psychological strategy workbook to know and grow your strengths -" [in Japanese], PHP Laboratory, 2002

(9) The Intervision Consortium : "[Getting Started] Team Building - How to make the strongest organization where $1+1$ is 2 or more -" [in Japanese], PHP Laboratory, 2007

(10) Kanako Hanyu, and Hisayoshi Inoue : "The Group Formation Supporting System for Effective Group Decision-making in Distance Learning Environment The Method of Group Formation on The Learner's Characteristics -" [in Japanese], Technical report of IEICE, ET2003-52, pp. 7-12, 2003

(11) Frank T. Lyman : "The responsive classroom discussion: The inclusion of all students", Mainstreaming digest : a collection of faculty and student papers, pp. 109-113, 1981

(12) Tiur Asih Siburian : “Improving Students' Achievement on Writing Descriptive Text Through Think Pair Share", International Journal of Language Learning and Applied Linguistics World, Vol. 3, No. 3, pp. 30-43, 2013

(13) Toshiyuki Shichido : "The Visual Analogue Scale used in Judging Clinical Effectiveness of Acupuncture and Moxibustion" [in Japanese], Japanese Acupuncture and Moxibustion, Vol. 46, No. 1, pp. 7-13, 1996

(14) Yuto Tanaka, Tomo Hiroyasu, and Utako Yamamoto : "Questionnaire survey" [in Japanese], IS Report, Medical Information System Laboratory of Doshisha University, January 29, 2015 